\title{
Thermal Analysis of Polyethylene Terephthalate (PET) -Coke Composites Prepared by Mechanical Alloying Technique
}

\author{
Debesh Devadutta Mishra ${ }^{*}$ \\ Department of Metallurgical and Materials Engineering, \\ Indian Institute of Technology Roorkee, Roorkee, India. \\ *Corresponding Author: debeshmaterials@gmail.com,debbsdmt@iitr.ernet.in \\ Tel:+91-9045760978,INDIA
}

\begin{abstract}
The thermal degradation behaviour of 10:90 and 90:10 blends of Polyethylene Terephthalate (PET) and petroleum coke has been investigated using mechanical alloying (milling) at $300 \mathrm{rpm}$ and for periods up to 1-10 hours. Milled specimens were characterised using SEM and x-ray diffraction; their thermal degradation behaviour was investigated using thermo-gravimetric analyser (TGA) for temperatures up to $1200^{\circ} \mathrm{C}$. Whereas PET specimens showed a tendency towards flattening out and increased surface area during collisions in ball mills, petroleum coke particles tended to break down into smaller particles. 10:90 and 90:10 blends of PET and coke showed significant microstructural evolution with increasing speeds and time including fracture, strain hardening and re-welding. X-ray diffraction results showed clear evidence for increasing amorphous component in petroleum coke without much influence on PET crystallinity. Thermogravimetric results showed a significant increase in the overall degradation and much higher weight losses associated with mechanical alloying. This study has shown that mechanical alloying could be used to modify the degradation behaviour of coke/plastic blends and corresponding yield during pyrolysis with implications for plastic waste management.
\end{abstract}


Keywords: PET, Petroleum Coke, Mechanical Alloying, Thermal studies, XRD

\section{Introduction:}

Plastics industries in the past decades have contributed towards the materialistic affluence in human community worldwide in different ways every year. The ever increasing amount of the need plastic goods creates abundance in the non biodegradable plastic wastes, which in turn helps in creating serious environmental problem. The conventional waste disposal methods like land filling and incineration creates obvious health hazards due to the production of toxic gases. Also the lack of land fills sites, leach ate hazards and ground water pollution are some of the other drawbacks for the conventional disposal [1-4]. The Ironical situation is that unlike metals and organic materials, plastic cannot be disintegrated with ease by micro organisms rather can be subjected to electrolyte corrosion, photo chemical processes and hydrolysis in a slow pace. The difficulties in waste disposal of plastics roots directly from the success of the plastic industries and the considerable increase in the recycling of the municipal wastes and post consumer sectors. Rather than a provisional situation like land filling there is no such rational solution to the disposal of plastic garbage. Mechanical recycling of the plastic wastes need sorting, selective collection, economic recycling and the utmost end market for the commercial value. The above processes are only useful for the plastic waste which are homogeneous and relatively clean but the plastic wastes of post consumer products i.e. dirty unsorted and small pieces of lightweight garbage, feed stock recycling and energy recovery must be considered [5].

The difficulty in the recycling process increases due to the immiscibility of the polymer wastes. Specifically beverage bottles contain various kinds of polymers. The difference in density between polyethylene terephthalate (PET), Low-density polyethylene (LDPE), high-density polyethylene (PET) and polypropylene (PP) differentiate PET from other three plastics; therefore 
the water floating is used to separate from other plastic mixtures. The later ones cannot be separated from each other as having nearly same theoretical density.

One of the most used thermoplastic polyester in synthetic fibres, films, beverage and liquid container is Polyethylene Terephthalate (PET). The high consumption of PET bottles in packaging industry lead to large amount of non biodegradable wastes, in turn increase serious environmental problems. Numerous methods like blending the recycled PET and virgin PET, polyolefins and polyesters and adding the chain extenders, chemically recycling ( methanolysis, glycolysis, hydrolysis and aminolysis) and incineration[6-10]. There are several studies showing the blending of the recycled PET with polyolefins and polyesters showing very interesting results for the ease of fabrication, mechanical properties and economically viable. Recycled PET also has been blended with polyethylene, Nylon, polypropylene and polyvinyl chloride [11-17].

Reactive blending doesn't give the advantage of the pulverization of the flake of the plastics to powders which when afterwards were a problem for the extrusion or melt processes. Researchers have adopted mechanical milling for the crushing of plastics and also are mixed with other plastics for their alloying. Researchers like Cavalieri et. al, Torkelson et.al have carried out the ball milling of the polymers with different compositions and parameters[18-22].

The physical properties and the mechanical properties have been noticed increasing due to the pulverization or ball milling of the plastics and the preferred one is cryogenic ball milling. The polymers like polyisoprene (PI) and polyethylene-alt-propylene (PEP) were milled to alloy with immiscible thermoplastic polymethyl methacrylate (PMMA) and the mechanical properties of the alloy were found better [23]. To improve the efficiency of pulverization carbon dioxide assisted ball milling was also carried out by Cavalieri [24]. 
Mechanical alloying induces cold welding and fracture in the polymer particles which creates the extension and shearing. The above process abstracts the hydrogen and helps in chain scissions, consequently producing free radicals. The formation of free radicals facilitates chemical cross-linking and chemical coupling of the different species. The dissimilar bond formation helps in compatibilizing the immiscible plastics and in some cases catalyst like $\mathrm{CO}_{2}$ is used to improve the pulverization and as the external energy to the polymer powders are given through the ball-ball collision and ball-vial collision, the $\mathrm{CO}_{2}$ is trapped between the ball and vial/ball absorbs the impact which creates a micro explosive evaporation of liquid $\mathrm{CO}_{2}$ and fragments the solid easily. Though some potential problems like the hindrance of cold welding due to the low diffusivity within different plastics, there is acceptable increase in the mechanical properties and physical properties in the polymer blends found when milled or alloyed [24]. In the polymers specifically Polyethylene Terephthalate (PET) used in food packaging industries have carbon as major constituents, which is an economical and abundant source of carbon. Due to the extensive cross linking, additives and fillers it is difficult for these plastics to be recycled. In the present study we will develop the fundamental knowledge essential for novel recycling of PET for different applications e.g., carbon anode (i.e., fused coke, in Hall-Heroult process used for producing primary aluminum) [25] and in steelmaking (in electric arc furnace) [26]. So that these areas will no longer rely exclusively on conventional carbonaceous materials (coke/coal) for its carbon requirement. The recycling strategy examined here is MA of PET and petroleum coke. The carbonaceous blends from metallurgical coke and PET have been prepared and studied using X-ray Diffraction (XRD), Scanning electron Microscope (SEM), Electron Diffraction Analysis through X-ray (EDAX), Thermal Gravimetric Analysis (TGA) and Differential Scanning Calorimetry (DSC). 


\section{Materials and Methods:}

The 'as received' powders of PET, HDPE and petroleum coke (PC) were milled in a high energy planetary ball Mill with 5:1 ball to powder ratio at $300 \mathrm{rpm}$ for 1-10 hours [Table-1]. The Petroleum coke powders were of the size of $100 \mu$ and the PET powders were prepared by crushing and grinding of $\mathrm{COKE}^{\mathrm{TM}}$ bottles (the containers without the cap). The PET powders were of uneven sizes like flakes. The Petroleum Coke and Polyethylene Terphthalate(PET) are mixed in a proportion of 10:90 and 90:10.Thermo gravimetric (TG) with simultaneous derivative thermogravimetric (DTG) and differential thermal analysis (DTA) of PET, PC and Mechanically Alloyed PET and PC mixtures were performed on a PerkinElmer Pyris Diamond thermal analyzer. Samples of $10-15 \mathrm{mg}$ were heated up to $1500{ }^{\circ} \mathrm{C}$ at a heating rate of $10{ }^{\circ} \mathrm{C} / \mathrm{min}$ in the inert atmosphere of dry nitrogen at a flow rate of $100 \mathrm{ml} / \mathrm{min}$. X-ray diffraction pattern (XRD) of PET and PC of MA blends were recorded on a Bruker AXS diffractometer using $\mathrm{Cu}$ $\mathrm{K} \alpha(\lambda=1.5418 \AA \dot{)})$ radiation and a nickel filter at $35 \mathrm{kV}$. The scan rate of $2 \% \mathrm{~min}$ was applied to

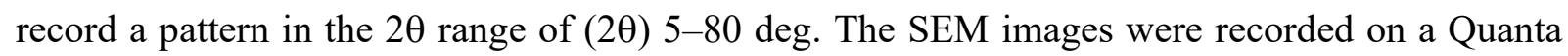
FEI 200 electron microscope and the samples were previously covered with gold thin layer.

Table 1: Milling parameters

\section{Results and discussion}

\subsection{Microstructural Evolution}

Mechanical alloying is the non equilibrium process for modifying the microstructure of contents through repeated process of cold welding and fracture. The morphological features of the initial powdersgets remorphed upon ball collisions at high speeds for prolonged mechanical alloying. FESEM micrographs show that PET, being a ductile part, easily gets flattened on milling; 
however the particles of Coke turned to be quite finer and show homogeneity shape and size. The Ball-powder-ball collisions result in the finer powder particles and the cold welding of the particulates are displayed as the formation of agglomerated lumps. The consequences of milling of powder depend on the basic characteristics of constituent particles, e.g., ductile particles end up with higher deformation with subsequently better agglomeration i.e., cold welding, whereas harder particles inhibit the re-welding processes.

Fig.1 shows the FESEM micrograph for PET-Coke (10+90) composition for (a) $1 \mathrm{~h}$, (b) $2 \mathrm{~h}$, (c) $5 \mathrm{~h}$ and (d) $10 \mathrm{~h}$ milled samples

The finer particles increase the cumulative surface area of the system, in turn facilitates the inter diffusion process which behaves as factor on the basis of which brittle Coke resulting in larger diffusivity over PET sites. On the other hand, extended periods of milling help in improving the work hardening and, consequently the brittleness of the particles. Therefore, higher extents of milling can result in finer particles, with harder phases. The FESEM micrographs Fig.(1(a-d)) shows for PET-Coke $(10+90)$ composition the particle sizes are getting lowered on increasing the extent of milling. But the same of that of the PET-Coke $(90+10)$ composition shows flattened particles in comparison to the earlier ones Fig.(2(a-d)). The flattening of the PET-Coke $(90+10)$ mixtures is attributed towards the ductility of the abundant polymer part (PET), which allows the plastic deformation inhibiting the brittleness and lower particle size as well. The abundance of the coke in the earlier composition increases the concentration of finer particle size due to its relativistic brittleness with respect to PET.

Fig. 2 shows the FESEM micrograph for PET-Coke (90+10) composition for (a) $1 \mathrm{~h}$, (b) $2 \mathrm{~h}$, (c) $5 \mathrm{~h}$ and (d) $10 \mathrm{~h}$ milled samples 


\subsection{Thermal decomposition behaviour}

DTA/TG curves of thermal decomposition of 10:90 blends of PET and PC are presented in Figure 4 for a range of milling extent. The comparative plot of the DTA curve (Fig.3 (a)) of the PET and Coke blends $(10+90)$ of different milling extent depicts the effect of mechanical alloying of the two contents on the thermal decomposition behaviour. The thermal analysis of the PET-Coke $(10+90) 1 \mathrm{~h}$ milled shows a endothermic peak corresponding to the melting of the PET at $242^{\circ} \mathrm{C}$, and when compared with blends of higher milling extent, the peak vanished due to the external energy introduced to the system by milling of the powder mixtures. Almost a small dip at the temperature within range $900^{\circ}-950^{\circ} \mathrm{C}$ for $1 \mathrm{~h}$ milled condition on increasing the milling extent became a bump and the height of the bump grows for higher milling extent.

The weight loss during thermal decomposition of the PET-Coke $(10+90)$ is determined using the TGA curves (Fig.3 (b-e)). There is a weight loss of $\sim 11 \%$ for $1 \mathrm{~h}$ milled sample within the range $367-470^{\circ} \mathrm{C}$. The weight loss in the temperature span corresponds to the boiling point of PET, where the actual boiling point of PET is $350^{\circ} \mathrm{C}$. The increase in the boiling point of the PET is due to the external energy provided by the milling of the powder blends and conversion of the boiling point from a particular temperature to a certain range is attributed towards the increase in the gibbs free energy of the system. Considering the various TGA curves for the above powder mixtures, it is well noticed from the plots that the theoretical boiling point has increased upto $401{ }^{\circ} \mathrm{C}$ (highest) for $5 \mathrm{~h}$ milled powder blends. The slope and the percentage weight loss during the boiling of PET displays a decreasing trend for higher extent mechanical alloying. The trend is noticed only upto $5 \mathrm{~h}$ milled samples. But for the observations of $10 \mathrm{~h}$ milled samples gives an idea that the slope of the boiling point temperature range is increased and there is a dip in the boiling point $\left(399^{\circ} \mathrm{C}\right)$. The span of the weight loss due to boiling of the 
PET is of $100^{\circ} \mathrm{C}$. The perturbation in above parameters is attributed towards the inclusion of the Coke powders inside the PET-flake matrix. Though it doesn't diffuse into the flakes and loses its physical presence (Fig.3 (e)), it decreases the Gibb's free energy of the system after its inclusion. The inhomogeneity in thermal decomposition is also attributed towards the higher percentage of Coke and lowest particle sizes of the PET Flakes (10h milled).

Fig. 3 shows the (a) comparative DTA analyses plots and TGA plots for (b) $1 \mathrm{~h}$, (c) $2 \mathrm{~h}$, (d) $5 \mathrm{~h}$ and (d) 10h milled samples for PET-Coke (10+90) composition.

According to Fig.4 (a) shows the differential thermal analysis of PET-Coke $(90+10)$ powder mixtures for various extents of milling. The Comparative analyses of the thermal decomposition behaviour depicts the melting point of PET which is actually $250{ }^{\circ} \mathrm{C}$ has been lowered to $242^{\circ} \mathrm{C}$ for $1 \mathrm{~h}$ milled powder. But upon milled for various periods the same varies as directly towards the milling time. This exhibit best upto the $5 \mathrm{~h}$ milled mixtures. The increasing trend is due to the increase in the Gibb's free energy of the system. The $10 \mathrm{~h}$ milled mixtures shows a drop in the melting point of $1{ }^{0} \mathrm{C}$, this deviation in the trend is attributed towards presence of $10 \mathrm{wt} \%$ Coke in the system. After Mechanical alloying of both the content, the coke is introduced in to the matrix of the PET flakes. Though the PET powders were used as the starting materials, due to its ductility the PET powders form flaky morphology after milling and the higher percentage of availability for this composition displays a better composite type of structure. The composite structures have a polymer matrix with coke as particulate reinforcement. Analysing the melting point of PET, the energy consumed during the process (endothermic peak), shows a decreasing behaviour. But the difference of the energy consumed remains $\sim 3$ units upto $5 \mathrm{~h}$ milled powder blends. The gap of the energy consumed within various powder blends has decreased in case of $10 \mathrm{~h}$ milled to $\sim 1 \mu \mathrm{V}$. The composite structures of PET and Coke induce the in homogeneity in 
the energy difference. The effect of mechanical alloying also can be seen in the DTA plots where at $\sim 1000^{\circ} \mathrm{C}$, there is a dip, which became an elevation and turned a broad exothermic peak when higher energy provided through milling to the system.

The TGA plots (Fig.4 (b-e)) determines the change in weight during thermal decomposition of the mixtures. The Thermogravimetric behaviour of the $1 \mathrm{~h}$ milled PET-Coke $(90+10)$ blends exhibits a trench at $350^{\circ} \mathrm{Cand}$ ends at $500^{\circ} \mathrm{C}$ showing a weight loss of $\sim 78 \%$. The above blend contains $90 \mathrm{wt} \%$ of PET powders, so after $1 \mathrm{~h}$ of milling also there is hardly any elevation in the boiling point.

Fig. 4 shows the (a) comparative DTA analyses plots and TGA plots for (b) $1 \mathrm{~h}$, (c) $2 \mathrm{~h}$, (d) $5 \mathrm{~h}$ and (d) 10h milled samples for PET-Coke $(90+10)$ composition.

But when we observe the samples milled for increased extents show an elevation in the boiling point and it is highest for the $2 \mathrm{~h}$ milled samples which show a dip in $\%$ weight loss. The weight loss is decreased due to the higher free energy of the milled samples, which helps in evaporating the volatile substances prior to the boiling point temperature. Though the weight loss for $2 \mathrm{~h}, 5 \mathrm{~h}$ and $10 \mathrm{~h}$ milled are almost the same, but the lowest of them is $\sim 64 \%$ for $10 \mathrm{~h}$ milled samples. The left over weight near the trench of boiling point is $\sim 31.5 \%$, highest among all for $10 \mathrm{~h}$ milled samples. The cumulative effect of milling and the fabrication of the composite structures add to the increase in weight left over, which can be seen best for the $10 \mathrm{~h}$ milled samples. Comparing both the series of samples for their thermo analytical behaviour, the melting of the PET is more prominent in PET-Coke $(90+10)$ composition due to its abundancy. The post melting elevation is more clarified in the PET-Coke $(90+10)$ within the range $950-1000^{\circ} \mathrm{C}$. The lower percentage of Coke, is responsible for the shifting of the post melting bump towards $950-1000^{\circ} \mathrm{C}$ with respect to PET-Coke (10+90). The Thermogravimetric analyses of the above two compositions provides 
better idea about the occurrence of Coke. For PET-Coke $(10+90)$ blends the weight loss trench at boiling point $\left(\sim 350^{\circ} \mathrm{C}\right)$ for various milling times displays a drop in the slope. When the composition for the above is reversed (PET-Coke $(90+10)$ ), the post boiling point trench in the TGA plots are quite prominent and the drop in slope on increasing the milling time is very minimal. The presence of PET affects the weight loss percentage of both series of samples. The weight loss percentage after gassifying of PET at boiling point shows a lot of difference with respect to each other. This confirms the phase conversion of PET at that point to gaseous phase. The left over final weight comparison gives the idea of the effect of presence of PET in the composition. Because the final weight remained after heating upto $1400^{\circ} \mathrm{C}$ can be comparable with the weight $\%$ of PET present in the blend. The minimal deviation of actual percentage $(\leq 4 \mathrm{wt} \%)$ is attributed towards the cumulative effect of volatile substances present in Coke, the formation of PET-Coke composite structures and the shifting of thermal behaviour due to the improve in the Gibb's free energy. But the later one is having more prominent effect with respect to others.

\subsection{XRD Analysis}

The Fig.5 (a,b), shows the diffraction pattern of mixtures milled at $300 \mathrm{rpm}$ for various periods of $1 \mathrm{~h}, 2 \mathrm{~h}, 5 \mathrm{~h}$ and $10 \mathrm{~h}$ for PET-Coke $((10+90)$ and $(90+10))$ compositions. The XRD spectrum shows major peaks as Polyethylene terephthalate and carbon. The peaks were more distinguished for carbon and shows diffused nature for polyethylene terephthalate. The non crystallinity of the polymer is responsible for the diffused peaks, though carbon is having crystal structure due to mechanical alloying the corresponding peaks display a broadened nature. Specifically PET-Coke $(10+90)$ show sharper peak patterns comparatively which can be attributed towards the higher percentage of Coke present. The peak patterns display, broader features for PET-Coke $(90+10)$ 
blends, due to the presence of higher percentage of PET. For 10h milling the peaks of both the series of samples exhibits the amorphization. So it can be inferred that mechanical alloying resulted in reducing/destroying the crystalline order in petroleum coke. This has also resulted in enhanced reactivity as indicated by the corresponding TGA curves. This result indicates that amorphous petroleum coke was much more reactive than crystalline coke showing significantly higher weight losses. This study has shown that the pyrolysis/degradation behaviour of petroleum coke and PET could be significantly modified through mechanical alloying of their blends.

Fig.5 shows diffraction pattern for (a) PET-Coke (10+90) and (b) PET-Coke $(90+10)$ compositions.

\section{Conclusions}

The PET-Coke powder blends $((10+90)$ and $(90+10))$ exhibit the effect of mechanical alloying by the formation of polymer-coke composite structures. The $10 \mathrm{~h}$ mechanically alloyed powder mixtures show the heterogeneity in thermo gravimetric behaviour. The intrusion of coke into the PET matrix helped in the decrease in the weight loss for the highest extent of milling. PET shows rarely change in its crystallinity upon milling, whether coke is subjected to amorphous nature hence facilitating the diffusion. The decrease in weight loss may be useful for fabricating this material as the electrode in an economically viable way for aluminium extraction process.

\section{Acknowledgements}

The author (DDM) acknowledges to MHRD, Govt. of India for the partial financial support and Institute instrumentation centre of Indian Institute of Technology, Roorkee for providing lab facility. 


\section{References:}

[1] Progelhof RC, Throne JL. Polymer Engineering Principles. Munich: Hanser, 1993.

[2] Rosen SL. Fundamental Principles of Polymeric Materials, 2nd edn. New York: Wiley, 1993.

[3] Fletcher BL, Mackay ME. A model of plastics recycling: does recycling reduce the amount of waste? Resour Conserv Recycl 1996; 17:141-51.

[4] Brown DT. The legacy of the landfill: perspectives on the solid waste crisis. In: Mustafa N, editor.

Plastics Waste Management: Disposal, Recycling, and Reuse. New York: Marcel Dekker, 1993.

[5] Association of Plastic Manufactures in Europe (APME), Annual Report 2008.Website: http://www.apme.org.

[6] Utracki LA. Polymer alloys and blends. Berlin: Hanser, 1990.

[7] Sperling LH. Polymeric multicomponent materials. New York:Wiley, 1997.

[8] Macosko CW, Guegan P, Khandpur AK, Nakayama A, Marechal P, Inoue T. Macromolecules 1996;29:5590.

[9] Lyatskaya Y, Gersappe D, Balazs AC. Macromolecules 1995; 28:6278.

[10] Feng Y, Weiss RA, Han CC. Macromolecules 1996; 29:3925.

[11]Farrell MP, Kander RG, Aning AO. J Mater Synth Proc 1996; 4:1996.

[12] Ahn D, Khait K, Petrich MA. J Appl Polym Sci 1995; 55:1431.

[13] Koch CC. In: Cahn RW, editor. Materials science and technology, 15. Weinheim: VCH, 1991.

[14] Bouilloux A, Ernst B, Lobbrecht A, Muller R. Polymer 1997;38:4775.

[15] Benjamin JS. Metall Trans 1970; 1:2943. 
[16] Lu L, Lai MO. Mechanical alloying. Dordrecht: Kluwer Academic, 1998.

[17] J.K. Shaw, J. Pan, Microstructural Science 19 (1992) 659.

[18] K. Klementina, J.M. Torkelson, Solid-state shear pulverization of plastics: a green recycling process, Polymer-Plastic Technology Engineering 38 (3) (1999) 445-457.

[19] A.P. Smith, H. Ade, K.C. Koch, S.D. Smith, R.J. Spontak, Addition of block copolymer to polymer blends produced by cryogenic mechanical alloying, Macromolecules 33 (2000) 1163-1172.

[20] A.P. Smith, H. Ade, K.C. Koch, S.D. Smith, R.J. Spontak, Solid-state blending of polymers by cryogenic mechanical alloying, Material Research Society Symposium 629 (2000) 691-696.

[21] A.P. Smith, H. Ade, C.C. Koch, R.J. Spontak, Cryogenic mechanical alloying as an alternative strategy for the recycling of tires, Polymer 42 (9) (2000) 4453-4457.

[22] F. Cavalieri, F. Padella, S. Bourbonneux, C. Romanelli, Mechano-chemical recycling of mixed plastic waste, retrieved from http://modest.unipa.it/conferences/2000/html/symp9/ P9Th01.pdf, 2000.

[23] A.P. Smith, J.S. Richard, H. Ade, S.D. Smith, C.C. Koch, High-energy cryogenic blending and compatibilizing of immiscible polymers, Advanced Materials 11 (15) (1999) 1277-1281.

[24]F. Cavalieri, F. Padella, High-energy mechanical alloying of thermoplastic polymers in carbon dioxide, Polymer 43 (4) (2002) 1155-1161.

[25]U. Grjotheim, and H. Kvande; 'Introduction to Aluminium Electrolysis. Understanding the Hall Heroult Process’; Aluminium Verlag GmbH (Germany), (1993) pp. 260.

[26]R. Preston; ‘American Steel’; Avon Books, New York, (1991). 


\section{Tables}

Table 1: Milling parameters

\section{Figures captions}

1. Fig.1 shows the FESEM micrograph for PET-Coke (10+90) composition for (a) $1 \mathrm{~h}$, (b) $2 \mathrm{~h}$, (c) $5 \mathrm{~h}$ and (d) $10 \mathrm{~h}$ milled samples

2. Fig. 2 shows the FESEM micrograph for PET-Coke $(90+10)$ composition for (a) $1 \mathrm{~h}$, (b) $2 \mathrm{~h}$, (c) $5 \mathrm{~h}$ and (d) $10 \mathrm{~h}$ milled samples

3. Fig. 3 shows the (a) comparative DTA analyses plots and TGA plots for (b) $1 \mathrm{~h}$, (c) $2 \mathrm{~h}$, (d) 5h and (d) 10h milled samples for PET-Coke (10+90) composition.

4. Fig.4 shows the (a) comparative DTA analyses plots and TGA plots for (b)1h, (c) $2 \mathrm{~h}$, (d) 5h and (d) 10h milled samples for PET-Coke $(90+10)$ composition.

5. Fig.5 shows diffraction pattern for (a) PET-Coke $(10+90)$ and (b) PET-Coke $(90+10)$ compositions. 


\begin{tabular}{|l|l|}
\hline Planetary Ball mill Details & Milling Parameters \\
\hline Milling Balls- Agate Balls & Milling Media-air \\
\hline Milling Jars- Agate Jars & Charge to Ball ratio-1:5 \\
\hline Jar capacity- $250 \mathrm{ml}$ & Milling speed- 300 rpm \\
\hline Time of milling- 10h & Vial Speed- 600 rpm \\
& Weight of initial charge- 30gms \\
\hline
\end{tabular}

Table 1: Milling parameters 

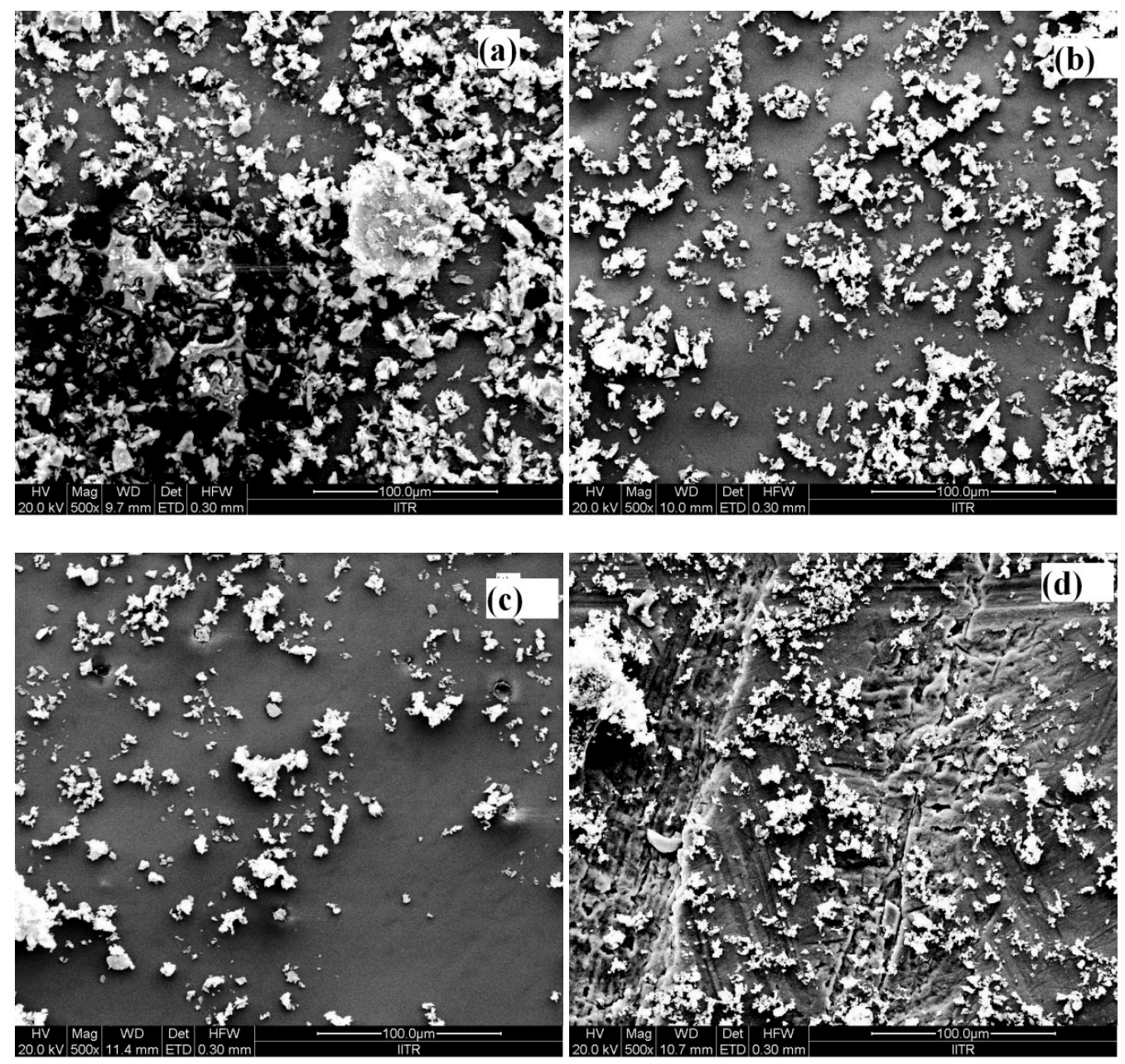

Fig.1 shows the FESEM micrograph for PET-Coke (10+90) composition for (a) $1 \mathrm{~h}$, (b) $2 \mathrm{~h}$, (c) $5 \mathrm{~h}$ and (d) $10 \mathrm{~h}$ milled samples 

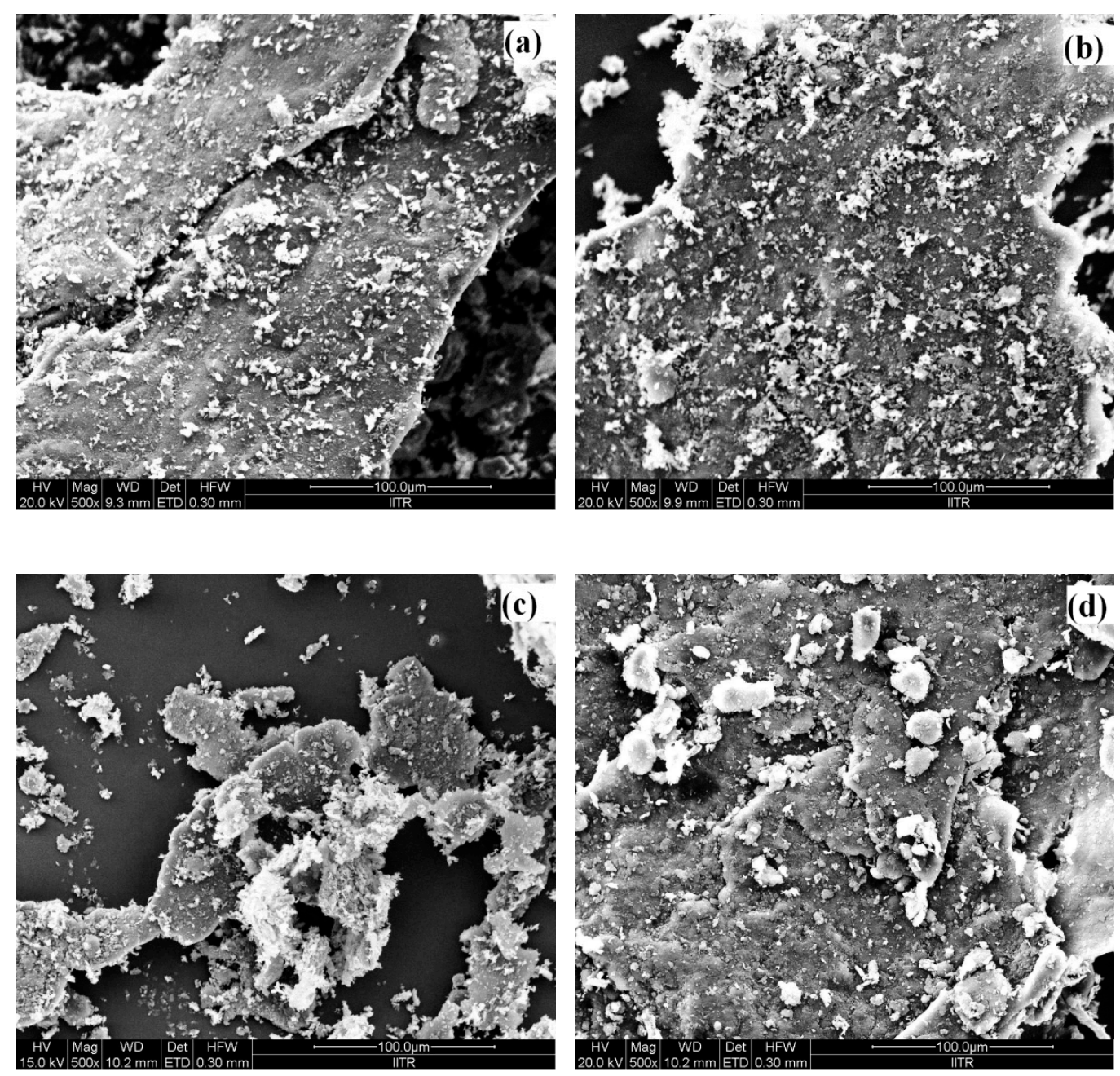

Fig. 2 shows the FESEM micrograph for PET-Coke $(90+10)$ composition for (a) $1 \mathrm{~h}$, (b) $2 \mathrm{~h}$, (c) $5 \mathrm{~h}$ and (d) $10 \mathrm{~h}$ milled samples 

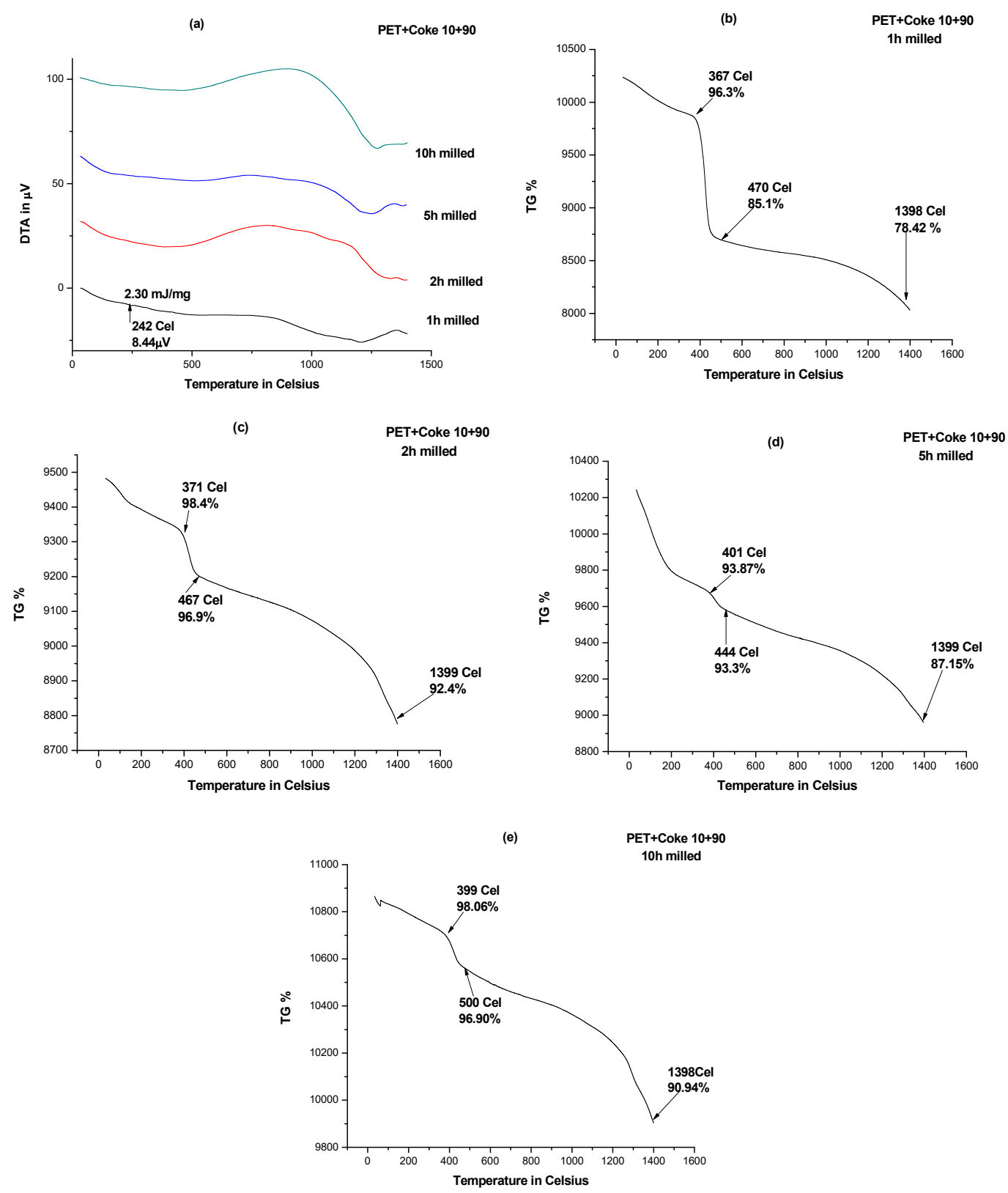

Fig. 3 shows the (a) comparative DTA analyses plots and TGA plots for (b) 1h, (c) 2h, (d) $5 \mathrm{~h}$ and (d) 10h milled samples for PET-Coke $(10+90)$ composition. 

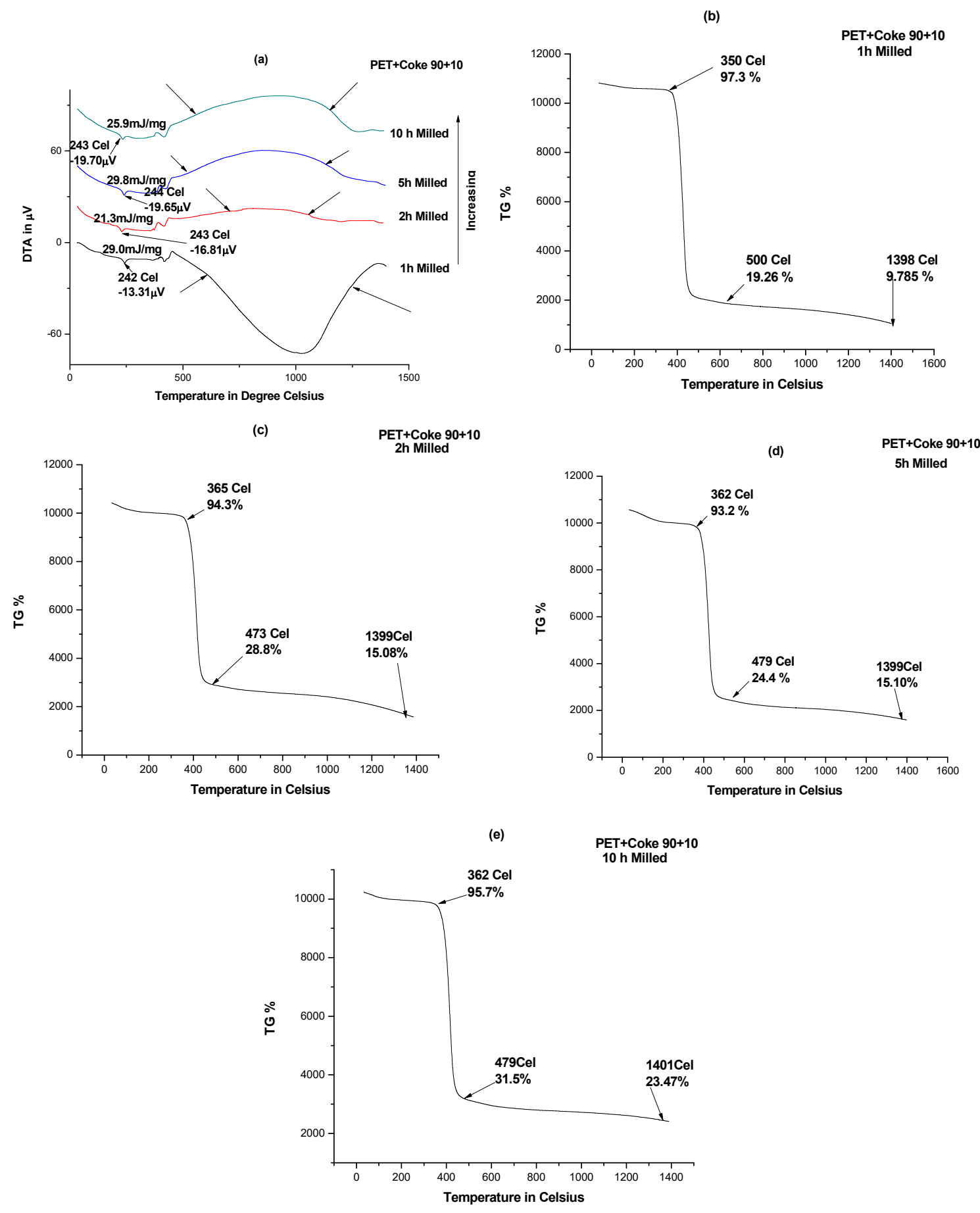

Fig. 4 shows the (a) comparative DTA analyses plots and TGA plots for (b) $1 \mathrm{~h}$, (c) $2 \mathrm{~h}$, (d) $5 \mathrm{~h}$ and (d) 10h milled samples for PET-Coke $(90+10)$ composition. 
(a)

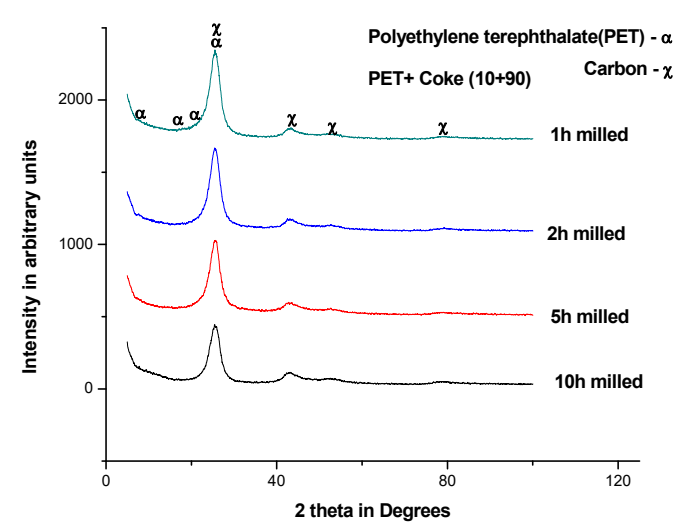

(b) Polyethylene terephthalate(PET) $-\alpha$

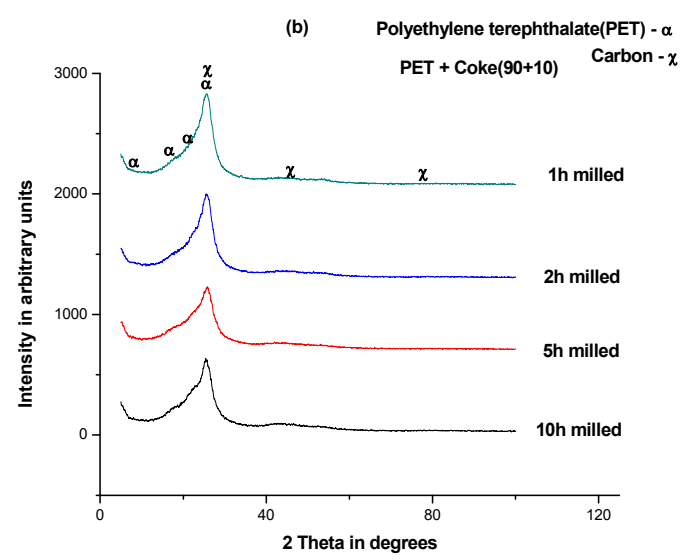

Fig.5 shows diffraction pattern for (a) PET-Coke (10+90) and (b) PET-Coke $(90+10)$ compositions. 